\title{
The conclusive role of postmortem computed tomography (CT) of the skull and computer-assisted superimposition in identification of an unknown body
}

\author{
Dorota Lorkiewicz-Muszyńska • Wojciech Kociemba • \\ Czesław Żaba • Marzena Labęcka • Małgorzata Koralewska-Kordel • \\ Monica Abreu-Głowacka • Agnieszka Przystańska
}

Received: 27 July 2012 / Accepted: 30 November 2012 / Published online: 13 December 2012

(C) The Author(s) 2012. This article is published with open access at Springerlink.com

\begin{abstract}
Computed tomography is commonly used in modern medicine, and thus, it is often helpful for medicolegal purposes, especially as part of the antemortem record. The application of postmortem computed tomography and $3 \mathrm{D}$ reconstruction of the skull in challenging cases is reported, and its valuable contribution to positive identification is discussed. This paper presents a case in which the body of an unknown individual is identified. Positive identification had not been possible despite a multidisciplinary examination. The postmortem use of computerized tomography and $3 \mathrm{D}$ reconstruction of the skull followed by the comparison of individual morphological characteristics of the viscerocranium showed the concordant points between the deceased and a missing person. Finally, superimposition using a 3D-reconstructed skull instead of the skeletonized skull demonstrated an adequate degree of morphological consistency in the facial images of the analyzed individuals that lead to positive identification. It was concluded that where other methods of personal identification had failed,
\end{abstract}

D. Lorkiewicz-Muszyńska $(\bowtie) \cdot$ C. Żaba $\cdot$ M. Łabęcka •

M. Koralewska-Kordel $\cdot$ M. Abreu-Głowacka

Department of Forensic Medicine,

Poznań University of Medical Sciences,

60-781 Poznań, ul. Święcickiego 6, Poland

e-mail: dlorkiew@ump.edu.pl

W. Kociemba

Department of Neuroradiology,

Poznań University of Medical Sciences, Poznań, Poland

A. Przystańska

Department of Anatomy, Poznań University of Medical Sciences,

Poznań, Poland the use of postmortem computed tomography had proved to be instrumental in the positive identification of the deceased.

Keywords Human identification · Skull · Computer tomography $\cdot$ Odontology $\cdot$ Superimposition

\section{Introduction}

As the skull provides valuable information about individual human characteristics, its use in personal identification of human remains is of primary importance in medicolegal proceedings.

Comprehensive comparative identification based on the skull depends on detailed anatomical, anthropological, and odontological studies. With a skull and antemortem radiographs of the skull or facial photographs, the technique of superimposing photographs with the radiograph of the skull on a scale of 1:1 can be used to evaluate the anatomical consistency between them. Although the technique is adequate, it also requires the investigation of the outline and topographical relationships of the skull to parts of the face, the facial tissue thickness, and correlations between various anthropometric points.

The presented case was firstly directed to a multidisciplinary forensic team, who concluded after arduous research, that another method should be implemented in order to identify the deceased.

The aim of this paper is to demonstrate how postmortem computed tomography and 3D computer-aided reconstruction of the head and skull can contribute to positive identification when used in a comparison process and superimposition test. 


\section{Case history}

The body of an unidentified elderly man was discovered. A preliminary investigation by police found an addressed letter in the man's jacket, and upon finding this letter, they assumed the deceased to be S. J., a man who was known to have been homeless for many years. Homeless individuals in the area where the body was discovered were interviewed by police and were able to confirm that the first name of the deceased was S., however they were not familiar with the individuals surname. As they had not seen each other for many years and his appearance had changed dramatically, the supposed brother of the unknown man was also unable to make a positive identification of the body.

After the body was found at the scene, it was transported to and investigated at the Department of Forensic Medicine, and, as there was no evidence of suspicious circumstances and no injuries were found either within the head or the rest of the body, the public prosecutor did not commission an autopsy. Due to the lack of an autopsy, the possible cause of death had not been clarified.

However, as identification was the primary goal, the considered opinion of the public prosecutor was that genetic and anthropological testing was, theoretically more likely to provide a positive identification.

\section{DNA examination}

The results obtained during the genetic analysis using a set of PowerPlex ${ }^{\circledR}$ ESX17 did not clearly confirm kinship in line brother-brother (Fig. 1). In order to obtain larger amounts of genetic information, the samples were analyzed using STR markers on chromosome Y (Fig. 2). The results connected the two individuals, but not in the male line. At this point in time, positive identification was still not possible. Due to the lack of other family members, further genetic analysis was pointless.

\section{Postmortem examination}

A comparison of photographic documentation of the missing person and the deceased individual was performed. A decision by the public prosecutor not to allow facial hair to be shaved from the deceased resulted in the analysis of features and parameters from photographic documentation proving inconclusive (Fig. 3). ${ }^{1}$

\footnotetext{
${ }^{1}$ According to Polish law, the public prosecutor is responsible for making decisions regarding human bodies. After genetic investigations had proved inconclusive, it was the public prosecutor who would not authorize facial hair to be removed, as potentially the face may be destroyed after defrosting. It was the view of the PP, that as the deceased had been homeless for many years, it was more likely that he would be identified by his comrades (who had only known him with facial hair) than by his brother, who had not seen him for many years and had only remembered him without a beard.
}

The dental records of the missing man were found, but any comparison with the dental status of the deceased was ruled out as he was edentulous. The identification of the facial characteristics using antemortem and postmortem photos of the man was possible but not positive. DNA examination did not reveal compatibility of the genetic profile. The case seemed to be unsolved.

\section{Computed tomography}

Due to the lack of conclusiveness in the previous steps of the medicolegal investigation, the public prosecutor was advised, and granted permission for, the use the computed tomography exclusively for the identification. Full body CT scans were obtained, but the CT of the skull was most crucial for identification. Neither the bones of the skull nor postcranial elements of the skeleton revealed the fractures.

The computer tomography of the deceased was performed using the SOMATOM Sensation 64 (Siemens). Slice thickness in our case was $0.625 \mathrm{~mm}$ as a standard for 64 slice CT scanner for further $2 \mathrm{D}$ and $3 \mathrm{D}$ reconstruction. This allows reconstruction of volumetric data (3D) on the accuracy level of about $1 \mathrm{~mm}$.

Window settings were as follows: WL between minus (-) 600 and minus (-) $500(-566)$; WW between 500 and $600(585)$. This Window setting was necessary to display soft tissue over the skeletonized skull. Window settings for the skeleton visualization were WW 90-100 and WL 230-250.

Three months had passed before the CT was performed, and the body being stored in a low temperature environment, it showed significant signs of drying. The graphic 3D reconstruction of the skull and the head was made using the software In Space (Fig. 4).

A reliability study had been carried out prior to the superimposition test. Ten skulls were scanned in CT, and the standard anthropological measurements were made in both skeletonized specimens (with use of anthropometric tools) and CT scanned images. Statistica 10.0 (StatSoft Inc., USA) was used for statistical analysis. The Shapiro-Wilk test and Student's $t$ tests were applied, and it was statistically established that the 3D model accurately depicts the original specimen. The photographs of the skeletonized skulls were then taken with the use of the standard digital camera (Canon Eos 50D). The image of the skull as seen in the photograph was compared to the image obtained in $3 \mathrm{D}$ reconstruction, and the high similarity in a shape and parameters was revealed.

Following the 3D reconstruction, the initial analysis of the face and bone features was conducted, and the results were compared with the antemortem photographs. Analysis of the CT images of the face and skull made it possible not 
a
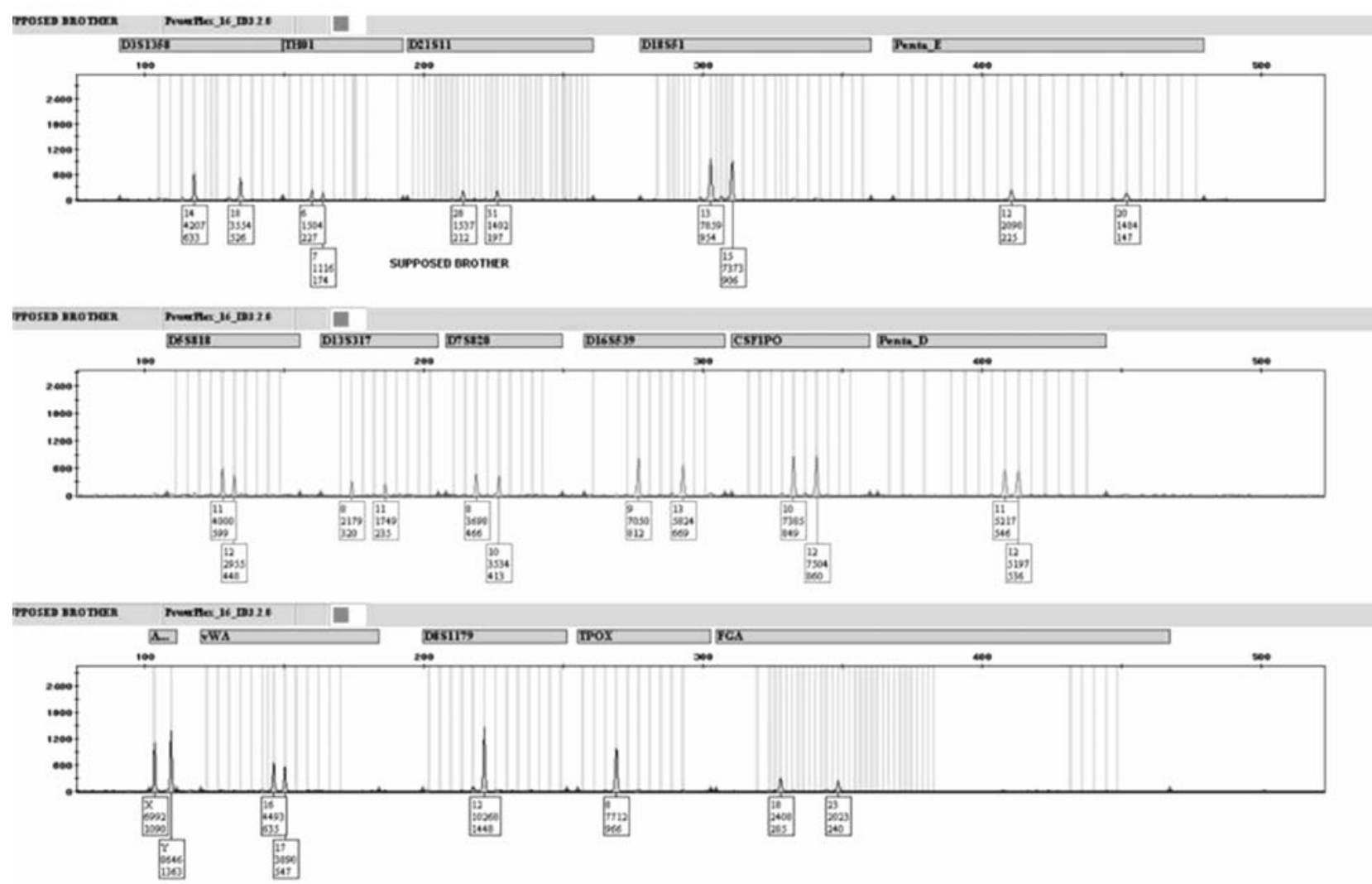

\section{b}
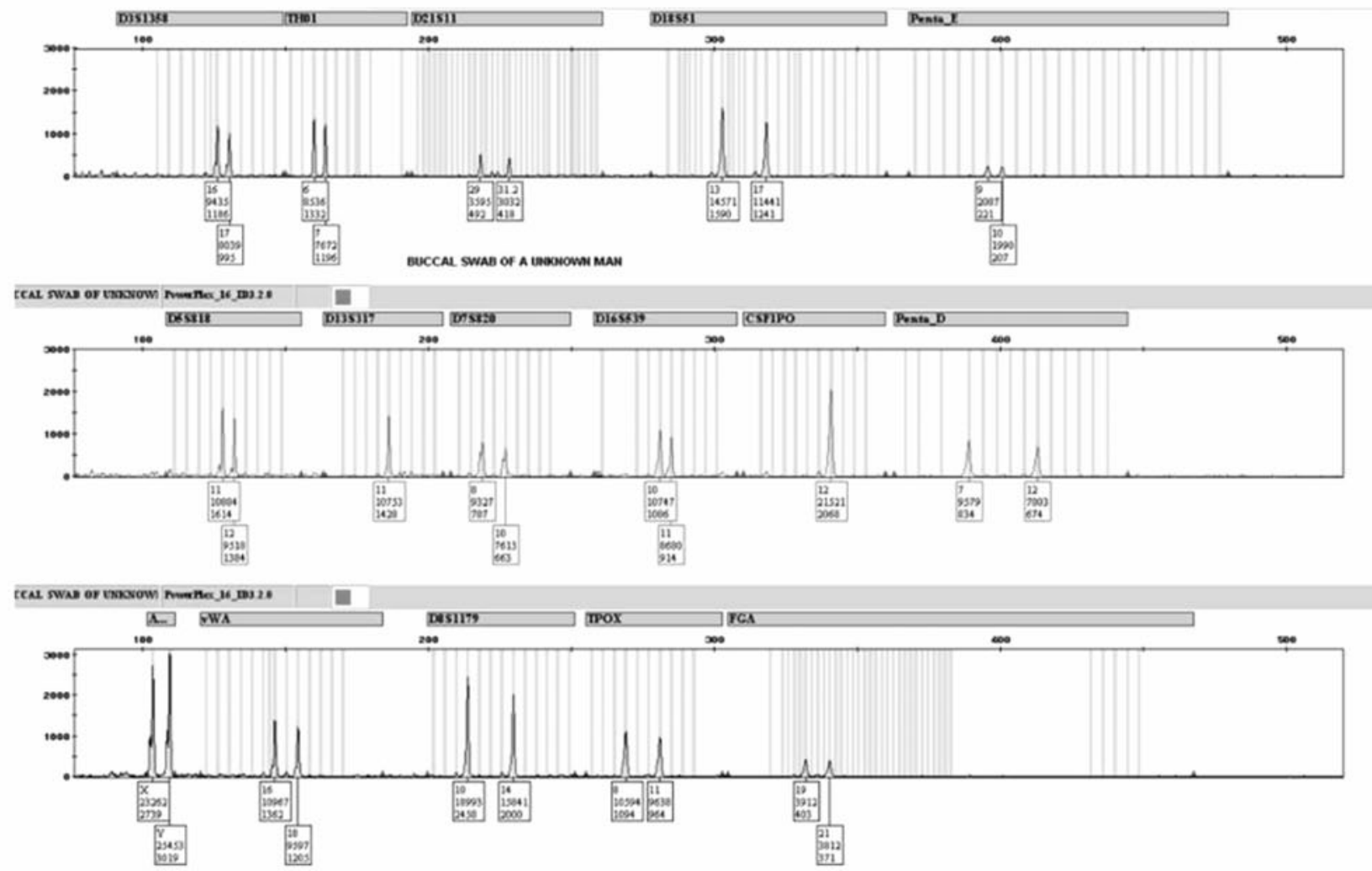

Fig. 1 Results of genetic analysis using PowerPlex ${ }^{\circledR}$ ESX17 (a supposed brother and b unknown body) 
a
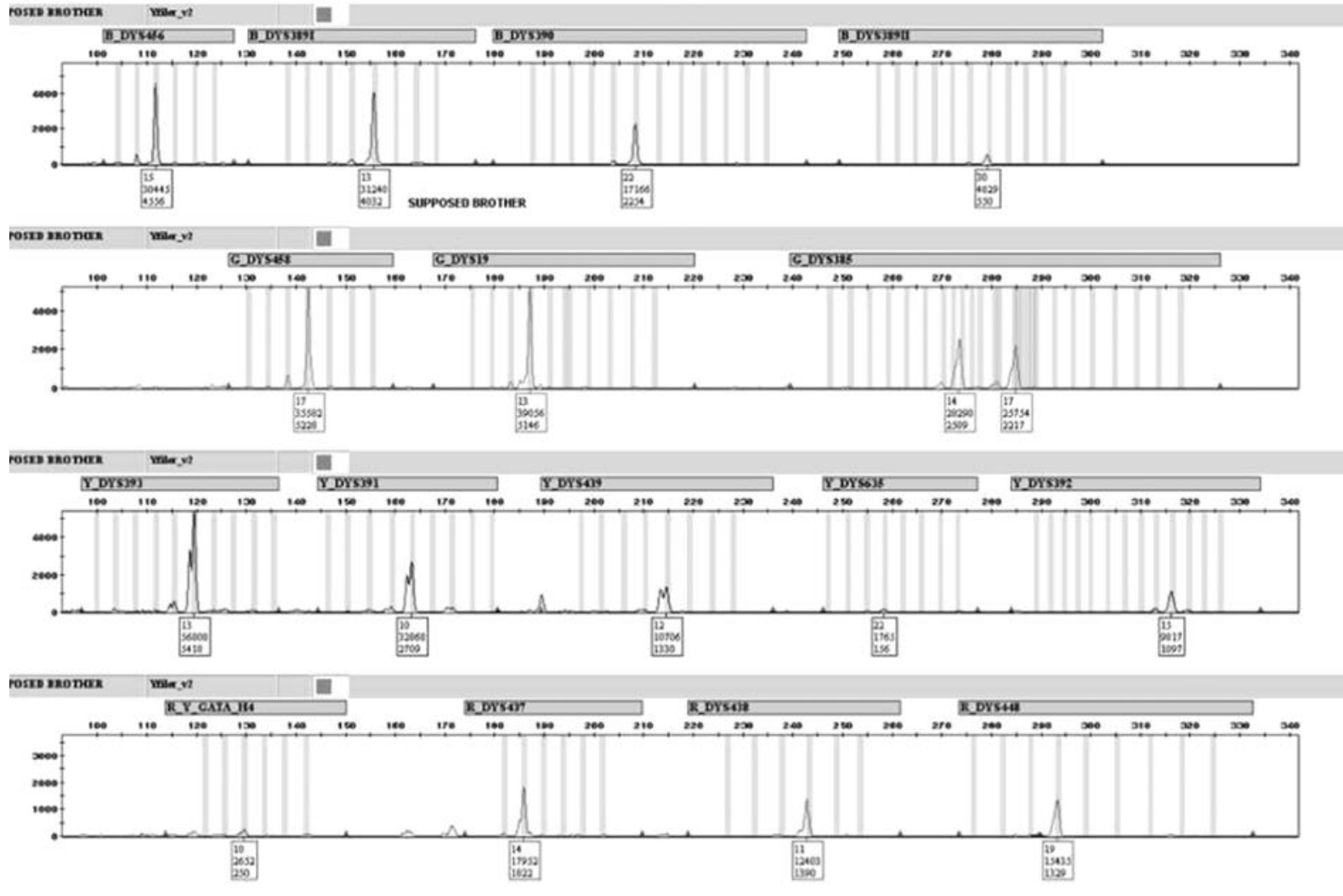

\section{b}
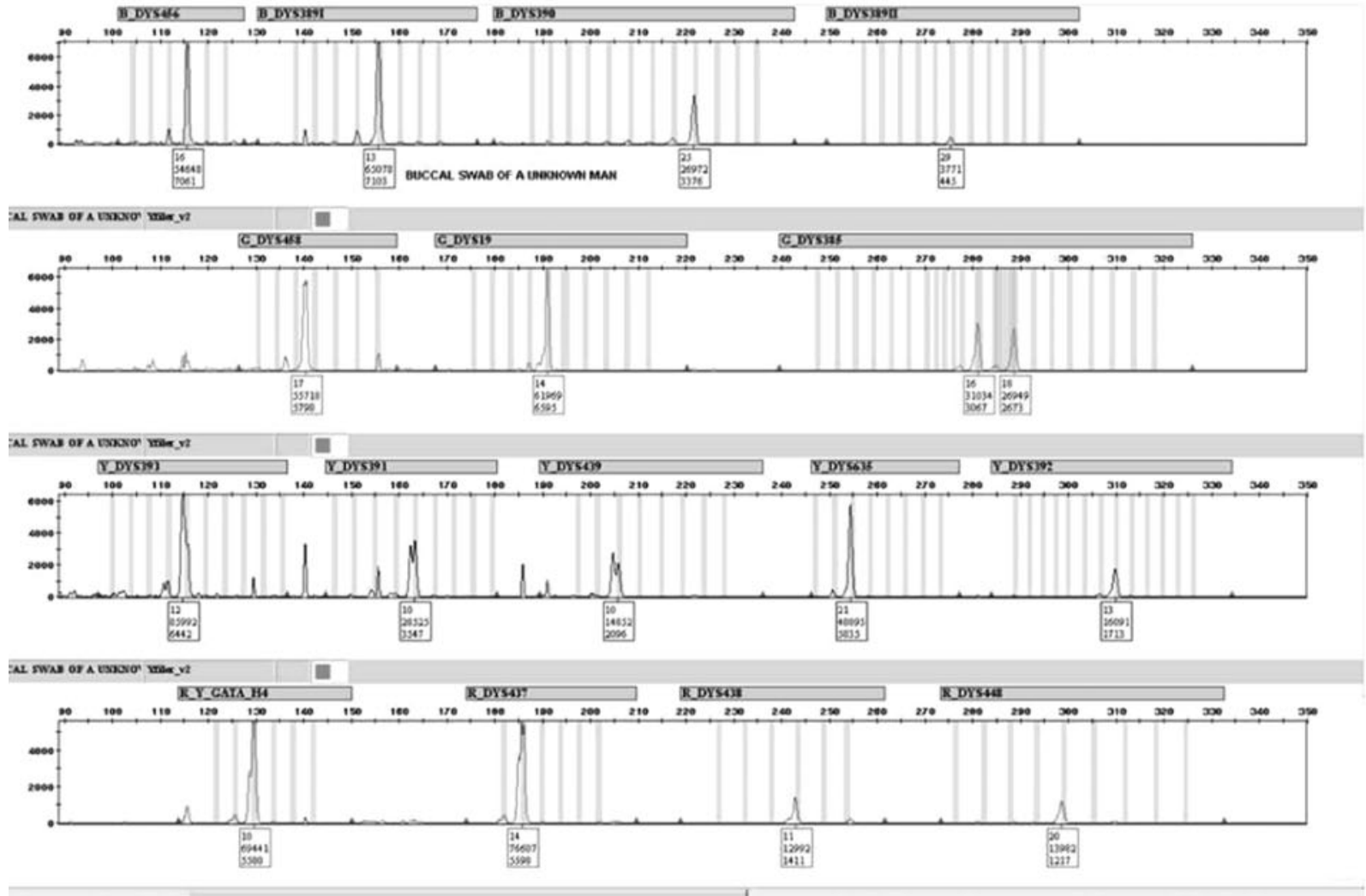

Fig. 2 Results of genetic analysis using STR markers on chromosome Y (a supposed brother and b unknown body) 

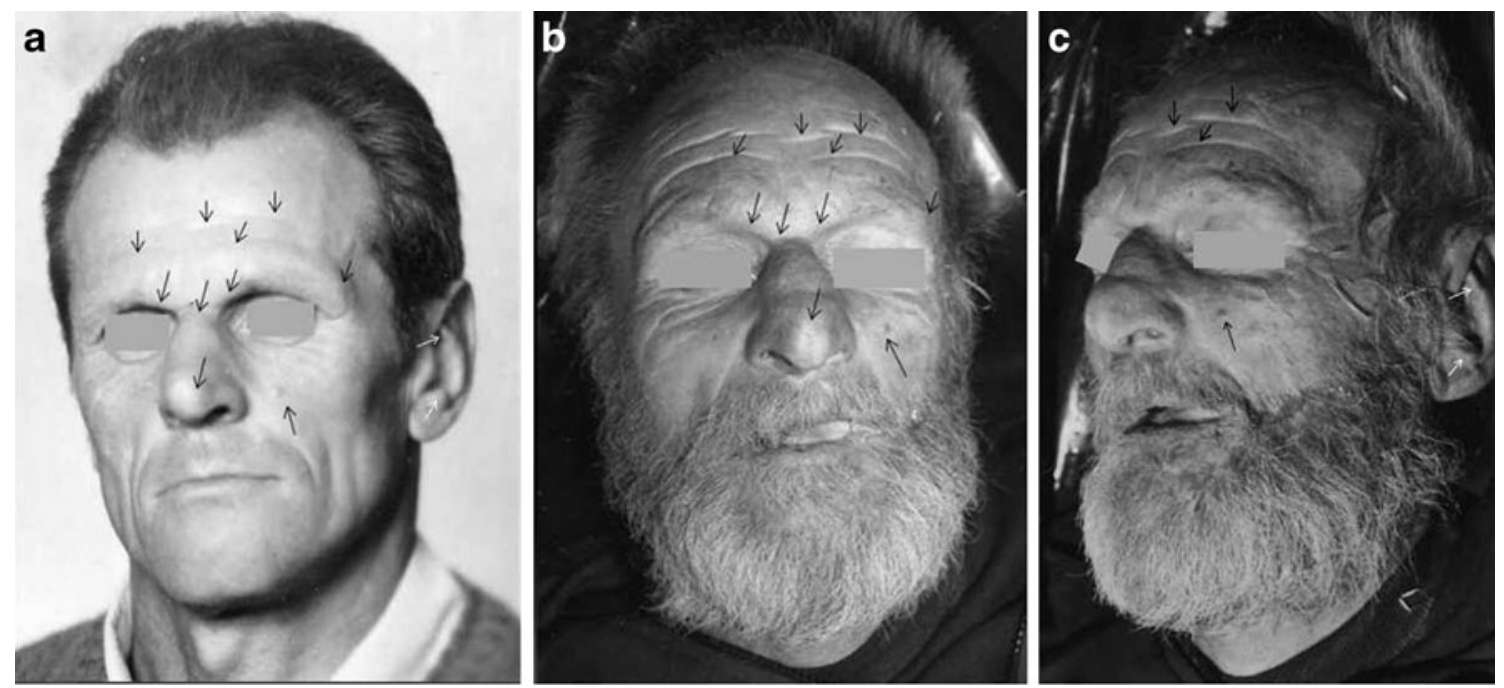

Fig. 3 A comparison of photographic documentation of the missing person (a) and the deceased individual (b, c) showed concordance in some features

only to identify and segregate elements which were anatomically unrecognizable in the body (the evidence of nasal bone fracture), but were also used to observe and record useful identifying features and parameters. Bony details of the viscerocranium, especially the typical curvature of the base of the mandible as well as the shape and length of the mandibular ramus were noted and showed relation to the antemortem appearance.

The relation of eye to bony orbit, the characteristic convexity of the supra- and infraorbital margins, as well as the shape of the orbit showed similarities. The facial characteristics as shown in the $\mathrm{CT}$ of the body showed a high degree of correlation with the facial features of the missing person (Fig. 5). Particularly important for this conclusion was the CT reconstruction of the lower-face region because this area of the dead body was not available for any other comparison due to the presence of facial hair.

The proportions of the face, particularly in the midface region (the relation of the external nose to the nasal aperture, small piriform aperture) were also distinctive. Based on a comparative analysis of the $\mathrm{CT}$ images of the face and skull with the antemortem facial features of the missing person, it was concluded that the reconstructed skull and head shown in the antemortem photographic documentation could potentially belong to the same person.

It was concluded that the computed tomography was superior in comparison to the performed autopsy in imaging of the shape and characteristics of bones and also revealed characteristic proportions of the viscerocranium (Fig. 6).

Computer-aided superimposition

The superimposition method had been applied to the head of the unidentified body as a means of making a positive identification. Currently, the standard craniofacial superimposition requires an actual skeletonized skull for the purpose of layering the skull with the facial image of a deceased person. However, in this study, the skull was replaced by a $3 \mathrm{D}$ reconstruction of the skull of the deceased which was superimposed with facial photographs of the missing individual.

Superimposition was made using graphic editing system Adobe Photoshop (Adobe Systems) with advanced image tools for maintaining the original ratio and size, brightness, contrast, intensity, color balance, color saturation, and brightness control.

Two Photoshop layers were created. The antemortem photograph of missing person (S. J.) was first scanned and then imported into the first layer. Afterwards, the image of the $3 \mathrm{D}$ model of the skull, oriented in the position most closely corresponding to the antemortem photograph, was imported into the second layer. The procedure of relative placement of two images according to one plane accompanied by simultaneous interpenetration of the images (superimposition one image over another) was then conducted.

During the superimposition procedure of the antemortem photograph over the skull and head images of the unidentified person, all image correlations as well as proper (1:1) scale of the head to the skull were controlled.

Superimposition using 3D-reconstructed skull images demonstrated compatibility of structural traits of all analyzed morphological elements of the skull and face (Fig. 6). An adequate degree of morphological consistency between the 3D-reconstructed skulls and persons in the facial images allowed for positive personal identification.

Shortly thereafter, it was revealed that the two men had one mother but different fathers, leading to the conclusion that they were stepbrothers. 

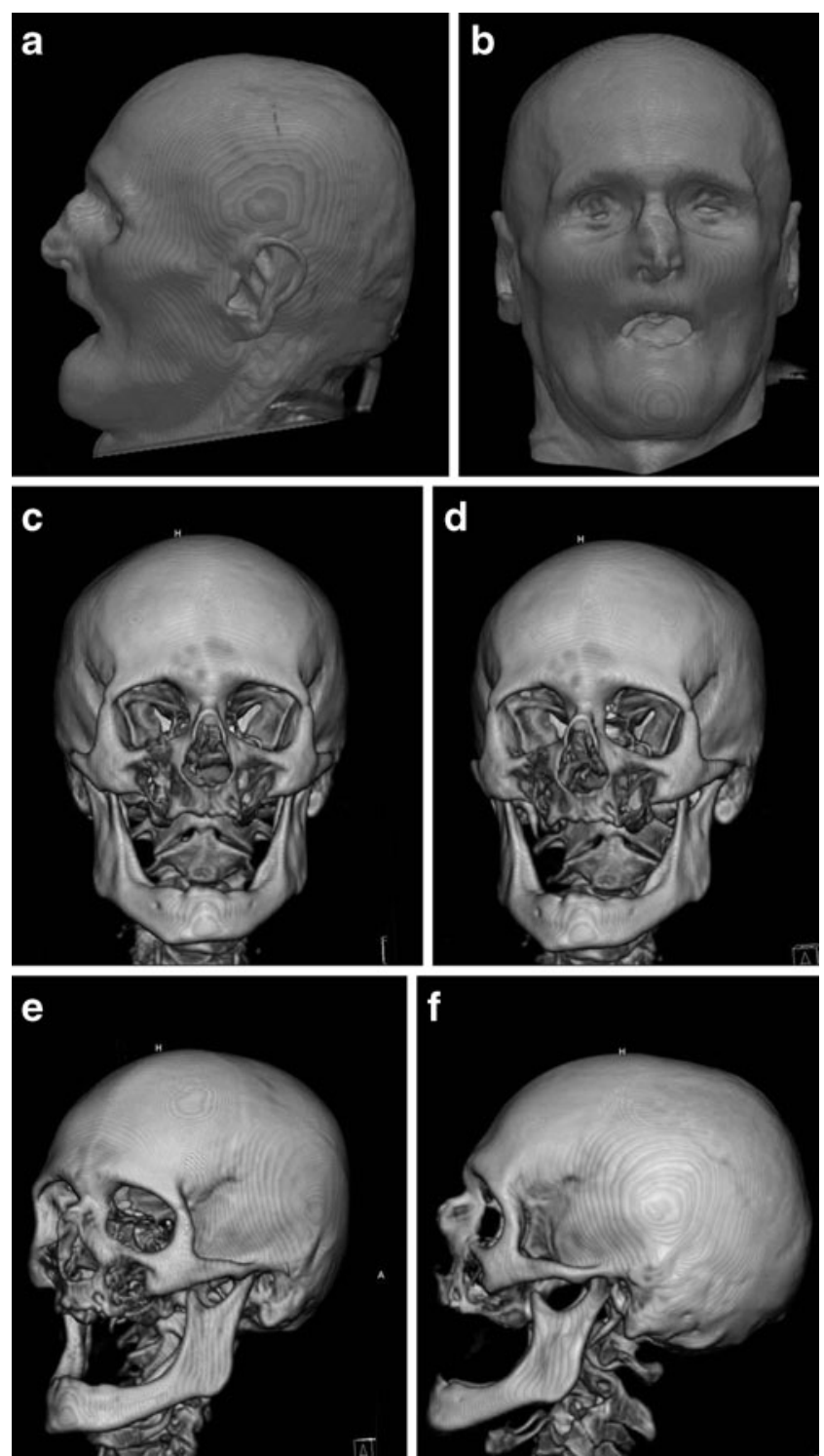

Fig. 4 Computer tomography of the deceased was performed using the SOMATOM Sensation 64 (Siemens). 3D CT reconstruction of the head $(\mathbf{a}, \mathbf{b})$ and the skull $(\mathbf{c}, \mathbf{d}, \mathbf{e}, \mathbf{f})$ were made using the software In Space

Taking into consideration the CT data of the body along with the $3 \mathrm{D}$ reconstructed image of the skull with computeraided superimposition, it was possible to positively identify the unknown individual as in fact being S.J. and in turn, this information was accepted as evidence in court proceedings.

\section{Discussion}

Radiology is a noninvasive method used to investigate the human body and as such, plays a significant role in medicolegal investigations and in the identification of human remains. The bony details such as form, size, shape, and individual characteristics are evident and consistent as shown by radiological means. Thus, the comparison of earlier with later radiological records is significantly important for forensic medicine and anthropology.

Computed tomography has been increasingly used to assist in medicolegal investigations [1]. The potential value of CT in the possible determination of the cause of death, estimation of age or visualizing features likely to enable personal identification is reported [2]. In some cases, the use of 3D-computerized imaging can provide strong medical evidence [3].

The aptitude of postmortem CT methods in the identification of human remains is also reported [4]. Computed tomography is commonly appreciated as it assists in confirming human identification, especially when antemortem $\mathrm{CT}$ records are used for comparison with postmortem radiographs $[5,6]$.

The contribution of CT may significantly contribute to forensic purposes, increasing the quantity and quality of information [7] and may play an important role in facilitating quick identification [8]. Furthermore, CT can be used for $3 \mathrm{D}$ reconstructions which in turn serve as comparative material for the superimposition tests in unidentified cases [9]. The 3D reconstructions of the skull performed as part of the forensic postmortem examination were previously described $[3,10]$ and its use as a valuable screening tool in identification procedures was suggested [10].

It is emphasized that the documentation in digital form provided by $\mathrm{CT}$ can be saved as data files and easily stored $[11,12]$ and it facilitates the distribution and evaluation of the work by transmitting CT data digitally [10].

This case demonstrates that CT is quick and extremely precise, and thus well suited as a supplement method to the routine autopsy. CT allows investigation of anatomic structures that are not easily available by autopsy and allows accurate analysis of bony structures. The possibility of being able to reconstruct a variety of images to permit multiple and recurrent analysis long after the event occurred is a further advantage of the applied method.

The postmortem CT analysis of the skull showed that indeed much of the postmortem information required for identification can be gathered from CT data. The following interpretation of the reconstructed images showed that the details provided by $\mathrm{CT}$ are much more valuable and determining for identification than obtained in other methods.

The contribution of the human skull for personal identification is out of the question. The viscerocranium is unique to each individual and remains constant throughout that individual's lifetime. The analysis of craniofacial structures can be challenging for forensic anthropologists and forensic pathologists in postmortem 
Fig. 5 Facial characteristics as shown in the CT images of the body (b) showed a high degree of correlation with facial features of the missing person (a)
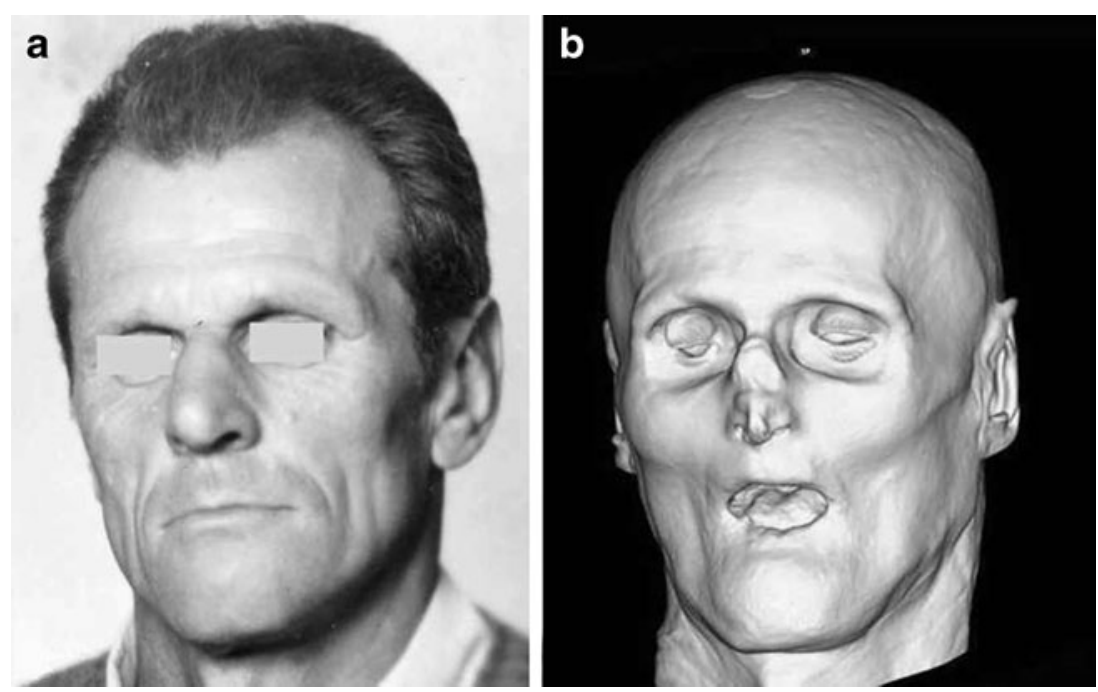

examinations. If the investigation is performed on the skeletonized human remains, the bony features are visible and easily accessible to experts. The situation is much more complex if the bones are still covered by
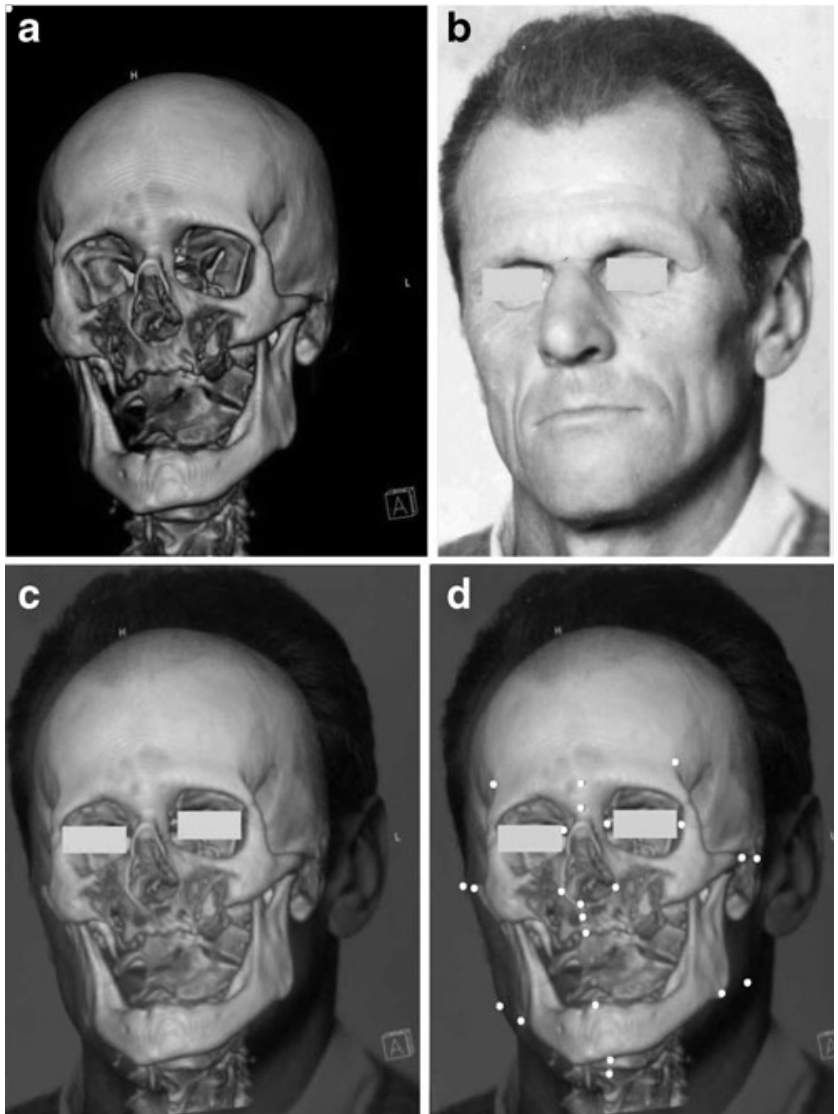

Fig. 6 Superimposition (c, d) using 3D-reconstructed skull CT image (a) and antemortem photograph of the missing person (b) demonstrated compatibility of structural traits of all analyzed morphological elements of both skull and face the soft tissues or for any (i.e., legal) reasons, an autopsy is not advised.

Computed tomography allows for $3 \mathrm{D}$ reconstruction of the skull and enables the evaluation of the individual morphological characteristics not available for examination if covered by the skin and soft tissues. Bony features, landmarks, shapes, and proportions are definitely distinct as observed in 3D reconstructions. The high quality of the images contributing to reconstructions of the skull are crucial for the projection of bony structures and are of the same probative value as the skeletonized skull usually used for the superimposition. Moreover, digital imaging can successfully replace the bony skull in the investigation. Ishii et al. [11] also reported that 3D skull reconstructions and the use of these images in superimposition demonstrates an adequate degree of morphological consistency between the 3D-reconstructed skeletonized skulls and the facial images and thus is effective for personal identification of unidentified bodies. However, the present paper demonstrates the use of CT in the scanning of the non-skeletonized body and confirms the effectiveness of this method if the skeletonized skull is not available for examination.

\section{Conclusions}

The computer-assisted superimposition applied for the comparison was crucial in determining positive identification, and it confirmed two investigated individuals to be the same person. We found the case remarkable due to the positive identification of a deceased individual by performing a CT scan and comparing multiple bony landmarks and images with corresponding features in antemortem photographs by superimposition. It is proved that the $3 \mathrm{D}$ reconstruction of the skull is as useful as a skeletonized skull for the superimposition test. Furthermore, the case illustrates the enormous potential for 
computerized tomography to complement the personal identification process.

Open Access This article is distributed under the terms of the Creative Commons Attribution License which permits any use, distribution, and reproduction in any medium, provided the original author(s) and the source are credited.

\section{References}

1. Woźniak K, Moskała A, Urbanik A, Kopacz P, Kłys M (2008) Pośmiertne badania obrazowe $\mathrm{z}$ rekonstrukcją 3D: nowa droga rozwoju klasycznej medycyny sądowej? Arch Med Sąd Krym 59 (2):124-130

2. Dedouit F, Telmon N, Costagliola R, Otal P, Florence LL, Joffre F, Rougé D (2007) New identification possibilities with postmortem multislice computed tomography. Int J Legal Med 121(6):507-510

3. Myers JC, Okoye MI, Kiple D, Kimmerle EH, Reinhard KJ (1999) Three-dimensional (3-D) imaging in post-mortem examinations: elucidation and identification of cranial and facial fractures in victims of homicide utilizing 3-D computerized imaging reconstruction techniques. Int J Legal Med 113(1):33-37

4. Smith DR, Limbird KG, Hoffman JM (2002) Identification of human skeletal remains by comparison of bony details of the cranium using computerized tomographic (CT) scans. J Forensic Sci 47(5):937-939

5. Haglund WD, Fligner CL (1993) Confirmation of human identification using computerized tomography (CT). J Forensic Sci 38 (3):708-712

6. Tatlisumak E, Yilmaz Ovali G, Aslan A, Asirdizer M, Zeyfeoglu Y, Tarhan S (2007) Identification of unknown bodies by using CT images of frontal sinus. Forensic Sci Int 166(1):42-48

7. Silva RF, Botelho TL, Prado FB, Kawagushi JT, Daruge Júnior E, Bérzin F (2011) Human identification based on cranial computed tomography scan: a case report. Dentomaxillofac Radiol 40(4):257-261

8. Blau S, Robertson S, Johnstone M (2008) Disaster victim identification: new applications for postmortem computed tomography. J Forensic Sci 53(4):956-961

9. Sakuma A, Ishii M, Yamamoto S, Shimofusa R, Kobayashi K, Motani H, Hayakawa M, Yajima D, Takeichi H, Iwase H (2010) Application of postmortem 3D-CT facial reconstruction for personal identification. J Forensic Sci 55(6):1624-1629

10. Sidler M, Jackowski C, Dirnhofer R, Vock P, Thali M (2007) Use of multislice computed tomography in disaster victim identificationadvantages and limitations. Forensic Sci Int 169(2-3):118-128

11. Ishii M, Yayama K, Motani H, Sakuma A, Yasjima D, Hayakawa M, Yamamoto S, Iwase H (2011) Application of superimpositionbased personal identification using skull computed tomography images. J Forensic Sci 56(4):960-966

12. Leth PM (2009) Computerized tomography used as a routine procedure at postmortem investigations. Am J Forensic Med Pathol 30(3):219-222 